\title{
Stay active for life: physical activity across life stages
}

This article was published in the following Dove Press journal:

Clinical Interventions in Aging

\author{
Elżbieta Biernat' \\ Monika Piątkowska² \\ 'Department of Tourism, Collegium \\ of World Economy, Warsaw School \\ of Economics, Warsaw, Poland; \\ ${ }^{2}$ Department of Organization and \\ History of Sport, Faculty of Physical \\ Education, Józef Pilsudski University \\ of Physical Education in Warsaw, \\ Warsaw, Poland
}

Purpose: This paper concerns participation of Poles aged 15+ years in leisure time and transport-related physical activity (PA) with a special focus on the life stages. The purpose of the paper was to analyze types of exercises, current and future behavior concerning PA, availability of sport and recreation facilities, and factors having the strongest relation with undertaking PA at a sufficient level according to pro-health recommendations of World Health Organization (WHO).

Patients and methods: A survey was carried out on the representative sample $(n=2,000)$. Respondents were classified in accordance to their life stages with a two-step cluster analysis. Relationships between meeting the dose of PA required for health recommendations and a membership in groups of life stages were evaluated using log-linear analysis. The strength of this relationship was expressed by the odds ratio. In order to capture relationships between meeting WHO recommendations and a set of explanatory variables, a predictive model was built.

Results: Life stages and various related events have a significant relation with a decrease of PA. Among groups of a particular risk, there are professionally active and unemployed people aged 50-64 years without children as well as retirees aged $65+$ years who do not meet WHO recommendations $(45.3 ; 50.4 \%$ and $47.6 \%)$. The unemployed and retirees more frequently $(p<0.0001)$ do not or cannot practice sport and do not think that a change of their situation is expected soon. However, $35 \%$ of professionally active people aged 50-64 years without children and $18.2 \%$ of unemployed people declare that they are currently not active but if they had the possibility, they would start practicing sport.

Conclusion: Campaigns promoting PA should be targeted at groups of a particular risk. Any attempts of increasing PA or changing tendencies of its decrease should consider life conditions of these persons, as well as their needs, motivations, and barriers.

Keywords: physical activity, life stages, professionally active 50+ without children, unemployed $50+$ without children, retirees without children, recommendations

\section{Introduction}

Physical inactivity and related modern-age diseases are a serious problem for public health. Despite numerous governmental initiatives, it has been observed that in many developing countries, the level of physical activity (PA) is decreasing. ${ }^{1}$ Researchers show that one of the reasons may be various social, physical, or psychological events in life $\mathrm{e}^{2,3}$ or experiencing a certain cycle of life characterized by significant traumas/ stages. ${ }^{4-7}$ Growing past childhood to adolescence, from school to work, retiring, starting a family, parental responsibilities - they change people's lives and change people's behavior (including behavior related to participation in PA). ${ }^{4-7}$

Allender et $\mathrm{al}^{1}$ distinguished five such turns, that is, employment status, residence, physical status, relationships, and family structure. Depending on accompanying
Correspondence: Elżbieta Biernat Department of Tourism, Collegium of World Economy, Warsaw School of Economics, Al Niepodległości 162, 02-554 Warsaw, Poland

Tel +48225646855

Email elzbieta.biernat@sgh.waw.pl BY NG terms.php and incorporate the Creative Commons Attribution - Non Commercial (unported, v3.0) License (http://creativecommons.org/licenses/by-nc/3.0/). By accessing the
work you hereby accept the Jerms. Non-commercial uses of the work are permitted without any further permission from Dove Medical Press limited, provided the work is properly attributed. For permission for commercial use of this work, please see paragraphs 4.2 and 5 of our Terms (https://www.dovepress.com/terms.php). 
conditions, for example, age, sex, nationality, or type of change they can have a positive or a negative influence on participation in PA. So, in case of employment status, retirement in particular, PA - for example, total ${ }^{8,9}$ or transportrelated physical activity (TPA; to and from work $)^{8}$ - can be reduced, ${ }^{3,8}$ especially among men ${ }^{10}$ and manual laborers. ${ }^{9}$ Some pensioners do not compensate for a decrease of PA by increasing participation in leisure time physical activity (LTPA), ${ }^{8}$ while some do. ${ }^{89}$ One example can be French retirees: not only do the number of persons participating in LTPA increase but also the time spent on exercises. ${ }^{11}$ It has been proven that during LTPA, the intensity of exercise usually drops but the frequency increases. ${ }^{8}$

Unemployment can favor increasing $\mathrm{PA},{ }^{12}$ but, as in the case of retiring, can have a negative influence on undertaking PA. ${ }^{2}$ By analogy, employment can cause both a drop of PA, ${ }^{13,14}$ on one hand, and an increase, ${ }^{15}$ on the other hand. A change of job can decrease $\mathrm{PA},{ }^{3}$ the same as change in residence, place, and circumstance. ${ }^{2,3}$ Researchers show that moving from a family home to a university can lead to social, physical, emotional, or cultural changes that result in short- or long-term decrease of PA. ${ }^{16}$

In the case of change in physical status (such as pregnancy and illness), opinions of scientists are varied. Devine et $\mathrm{al}^{6}$ and Grace et $\mathrm{al}^{17}$ did not observe any changes in physical exercise due to pregnancy, and others in relation with cancer. ${ }^{18-20}$ However, a review of 31 studies $^{21}$ reveals that PA related to professional work as well as LTPA drops. This fact is most often observed among women who are older and pregnant, married, from multi-children families, of a lower material status, and lower level of education. ${ }^{21}$ Similarly, patients with advanced progression of cancer are less active than healthy persons. ${ }^{22}$ Different conclusions are presented by Satia et al, ${ }^{23}$ proving an increase of participation in PA of people with cancer, which is explained in a supplementary action of PA coping with illness thanks to PA and emotional concern referring to waiting for treatment. ${ }^{24}$

Conclusions from cross-sectional studies concerning relations between changes in relationships (from being single to married or vice versa - divorce, separation, widowhood) with PA are also inconsistent. Some claim that people in relationships are less active than single, widowed, or divorced persons, ${ }^{25-27}$ while others state the opposite. ${ }^{28}$ More often, PA is the domain of single men and women ${ }^{26}$ and women in informal relationships and widows. ${ }^{27}$ However, there is also proof for the converse, documenting a drop of PA among recently widowed older women ${ }^{29}$ as well as divorced men and widowers. ${ }^{30}$
Changes in family structure, such as parenthood, ${ }^{2,14}$ or a birth ${ }^{27}$ are related to decreased participation in PA. However, PA can also be higher in case when children mobilize parents to active spending of free time ${ }^{31,32}$ or when parents motivate themselves when children move away from a family home. ${ }^{33}$

Summing up, current studies indicate significant changes in undertaking PA, resulting from certain life events and going through life cycles. However, this field is neither studied nor explained. There are many ambiguities and contradictions resulting from, for example, using various methods of measurement and evaluation of PA or accompanying conditions such as age, sex, or nationality of respondents. The current state of knowledge is mainly based on studies from the USA, Canada, and Australia. Generalization of such results for various countries can be limited. In light of changing indicators of participation in PA, this is a crucial research field for scientists from all over the world. Thus, the aim of this work was the analysis of participation in PA (LTPA and TPA) of a representative group of Poles, with a special focus on the life stages. Analyses concerned a type of exercise, current and future behavior concerning PA, availability of sport and recreation facilities, and which factors have a strongest relation with undertaking PA at a sufficient level (according to pro-health recommendations of World Health Organization [WHO]). Results of this work can be a significant indicator for building strategies of the promotion of PA in Poland, including addressing it to people at various stages of life as a target group.

\section{Materials and methods}

Survey studies called "Physical Activity" were conducted in autumn 2016 by order of the Ministry of Sport and Tourism. Surveys were conducted by trained and supervised pollsters from Growth from Knowledge (GfK) Computer Aided Personal Interviewing (face-to-face omnibus) (CAPIBUS), using computer-assisted personal interviews. Questions were formulated in a form equally readable for all respondents. The ethics committee of the Polish Academy of Sciences approved the study (approval number KEwN/60/2014) in accordance with the Declaration of Helsinki (2004). All participants provided written informed consent or legal guardian written informed consent for those under the age of 18 years.

The study was conducted on a nationwide representative sample of Poles $(n=2,000)$ aged $15+$ years $(25.6 \%-$ 15-29 years old, 16.7\% - 30-39 years old, 14.9\%-40-49 years old, $18.9 \%-50-59$ years old, and $24.1 \%-\geq 60$ years old). The sample included respondents with primary 
education $-24.0 \%$, vocational education $-23.5 \%$, secondary education $-34.2 \%$, and higher education $-18.4 \%$. A total of $62.6 \%$ were married, $23.7 \%$ single, $4.7 \%$ divorced/ separated, and $9.0 \%$ widowed. For $30.4 \%$, average monthly gross income (per capita in household) was at the level of 3,500-4,999 PLN/C841-1,200, for 28.0\% - 2,000-3,499 PLN/C481-840, for 27.3\% - $\geq 5,000$ PLN/C1201, and for $14.4 \%-<2,000$ PLN/€480.

Due to the fact that going through life cycles is characterized by crucial (distributed over time) transitions, the results were presented on the basis of a division of respondents into eight groups (similar in the scope of particular attributes characteristic for a life stage) (Table 1).

\section{Methods of data collection and analysis}

The research tool was a questionnaire composed of 13 questions (four on LTPA and TPA; one on current and future behavior of respondents concerning undertaking sport activity; two on sport and recreation infrastructure; and six on satisfaction with the infrastructure). Questions related to PA were based on the Polish version of the International Physical Activity Questionnaire (IPAQ).$^{34}$ They asked for each LTPA (vigorous physical activity [VPA] and moderate physical activity [MPA], walking) and TPA (walking, cycling/rollerskating). According to the IPAQ methodology, ${ }^{35}$ only efforts from last week, lasting $>10$ minutes at one stance, were taken into consideration. The next two questions from the part on PA concerned types and time spent per week on disciplines of sport specified by respondents (regularly practiced).

Information about current and future behavior of respondents concerning sport activity were collected on the basis of their choices from the following: 1) I do not want or cannot practice sport and I do not assume that my situation will change soon; 2) currently, I am not physically active, but if I had such a possibility, I would start practicing sport; 3) sometimes, I practice sport but I need a special incentive (eg, invitation by friends, nationwide actions); 4) I think that sport is healthy and I try to practice it as often as possible; and 5) sport is my way of life, thus I train everyday.

Questions also concerned sport and recreation infrastructure (open and closed facilities) available in the nearest neighborhood (up to a 30-minute walk from the place of residence), frequency of using it, and satisfaction with it (expressed using a 5-grade Likert scale: 1 - very unsatisfied; 5 - very satisfied).

Indexes of LTPA and TPA of Poles were calculated on the basis of data collected using IPAQ. They were expressed in metabolic equivalent of task (MET) units - minutes/week.
(1 MET corresponds to the consumption of $\mathrm{O}_{2}$ during resting and $=3.5 \mathrm{~mL} \mathrm{O}_{2} / \mathrm{kg}$ of body mass per minute. $)^{36}$ Indicators amounted to a sum of weekly energy expenditure of respondents: in the case of LTPA - coming from three types of efforts (ie, vigorous, moderate, and walking), in the case of TPA - two types (ie, walking, and cycling or roller-skating). Weekly energy expenditure of each activity was calculated by multiplying the MET number attributed to it (vigorous $8 \mathrm{MET}$, moderate - 4 MET, walking - 3.3 MET, cycling/ roller-skating - $6 \mathrm{MET}$ ) by the number of days of practicing it per week and time duration in minutes per day. On the basis of the sum of the evaluated indicators of LTPA and TPA, respondents were divided into those meeting and those not meeting the pro-health dose recommendations of PA as specified by the WHO. ${ }^{37}$ The first group comprised individuals taking part in MPA for $\geq 150$ minute/week or VPA for $\geq 75$ minute/week or walking for $\geq 150$ minute/week, or an equivalent of the combination of all activities (LTPA, TPA) exceeding $600 \mathrm{MET}$-min/week.

\section{Statistical analysis}

Statistical calculations were conducted using IBM $^{\circledR}$ SPSS $^{\circledR}$ Statistics ver 22 (IBM Corporation, Armonk, NY, USA).

First, respondents were classified in accordance to their life stages. A two-step cluster analysis was conducted in order to identify groups of observation (similar in the scope of particular traits), naturally existing in a set. The two-step method was used due to the presence of both qualitative variables (professional status) and quantitative variables (age, number of children, and marital status). This resulted in eight groups regarded as characteristic for particular life stages. The obtained Silhouette index was at the level of 0.6 and regarded as a satisfactory measure of coherence and distinctiveness. ${ }^{38} \mathrm{~A}$ description of life stages is presented in Table 1.

Descriptive statistical analysis was conducted (using characteristics of analyzed variables) using mean average $(\bar{x})$, standard deviation $( \pm \mathrm{SD})$, or fraction $(\%)$.

In order to verify if the analyzed variables (LTPA: VPA and MPA, walking; TPA: walking, cycling/rollerskating) were characterized by a normal distribution, the Kolmogorov-Smirnov test was used for a single sample. As the above assumption did not hold good for dependent variables $(p<0.05)$, statistical inference was based on the chi-square $\left(\chi^{2}\right)$ test and Kruskal-Wallis one-way analysis of variance. Relationships between meeting and not meeting the dose of PA required for health recommendations (according to WHO) and membership of respondents to 


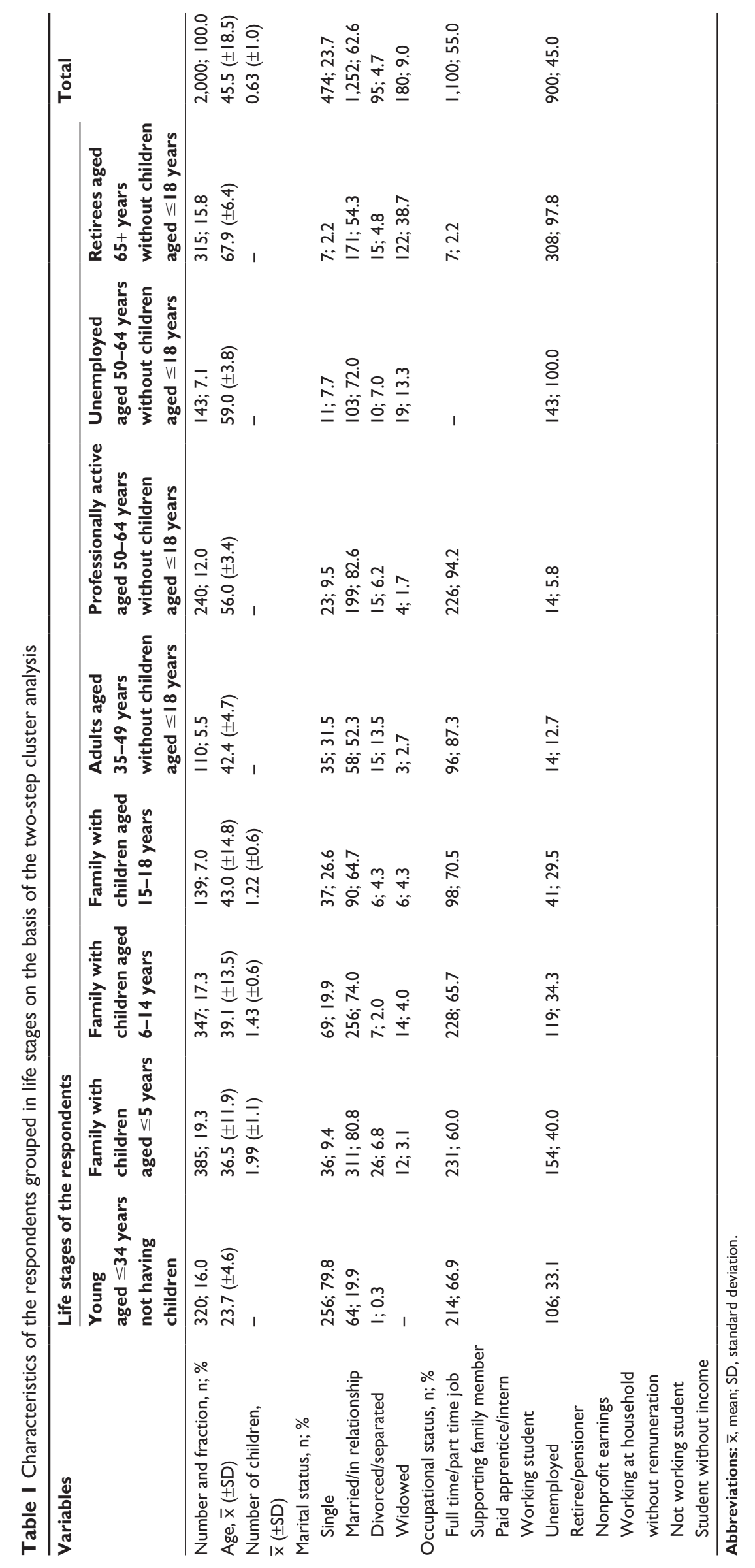


particular analyzed groups of life stages were evaluated using the log-linear analysis. The strength of this relationship was expressed by the odds ratio (OR) with $95 \% \mathrm{CI}$. The level of significance was $\alpha=0.05$.

In order to capture relationships between a categorical dependent variable (meeting WHO recommendations was the target variable) and a set of explanatory variables (life stages, declarations concerning current and future sport behavior, practiced disciplines of sport, using and satisfaction with sport infrastructure), a predictive model was built: a chi-squared automatic interaction detection (CHAID) decision tree. ${ }^{39}$ Due to lack of data, 1,623 cases were used for its construction (from the initial set of data of size $n=2,000$ ). The chi-square test and maximum likelihood classification were used to compare different categorical variables. These were classified into a binary or higher order series by the most significant predictor. The significance level for node splitting of the decision tree in CHAID was $p<0.05$. The estimated error of risk in the model was 0.281 , and the standard error was 0.011 .

\section{Results}

The study sample $(\mathrm{n}=2,000)$ was grouped (on the basis of cluster analysis) in eight heterogeneous groups, characteristic for particular life stages. Respondents were classified as: 1) young aged $\leq 34$ years not having children $-16.0 \%$; 2) family with children aged $\leq 5$ years $-19.3 \%$; 3) family with children aged $6-14$ years $-17.3 \%$; 4) family with children aged $15-18$ years $-7.0 \%$; 5 ) adults aged $35-49$ years without children aged $\leq 18$ years $-5.5 \% ; 6$ ) professionally active aged 50-64 years without children aged $\leq 18$ years $12.0 \%$; 7) unemployed aged $50-64$ years without children aged $\leq 18$ years $-7.1 \%$; and 8 ) retirees aged $65+$ years without children aged $\leq 18$ years $-15.8 \%$. Main characteristics of the distinguished clusters are presented in Table 1.

The mean value of declared PA in the whole analyzed group was 2,079.9 $( \pm 3,293.5)$ MET-min/week, including LTPA $1,110.0( \pm 2,050.3)$ and TPA $-969.9( \pm 1,703.1)$ (Table 2).

In case of participation in LTPA, significant differences were noted ( $p<0.001)$, depending on the life stage. VPA was most often expressed by young people aged $\leq 34$ years not having children $[705.0( \pm 1,891.7)$ MET-min/week] and those categorized as families with children aged $15-18$ years [491.0 $( \pm 1,229.4) \mathrm{MET}-\mathrm{min} /$ week]. Elderly people, that is, retirees aged $65+$ years without children aged $\leq 18$ years $[55.2$ $( \pm 229.6) \mathrm{MET}-\mathrm{min} / \mathrm{week}]$ and the professionally active aged $50-64$ years without children aged $\leq 18$ years $[74.0( \pm 538.0)$ MET-min/week] undertook VPA least often. Similar results were obtained in the case of MPA, most often declared by

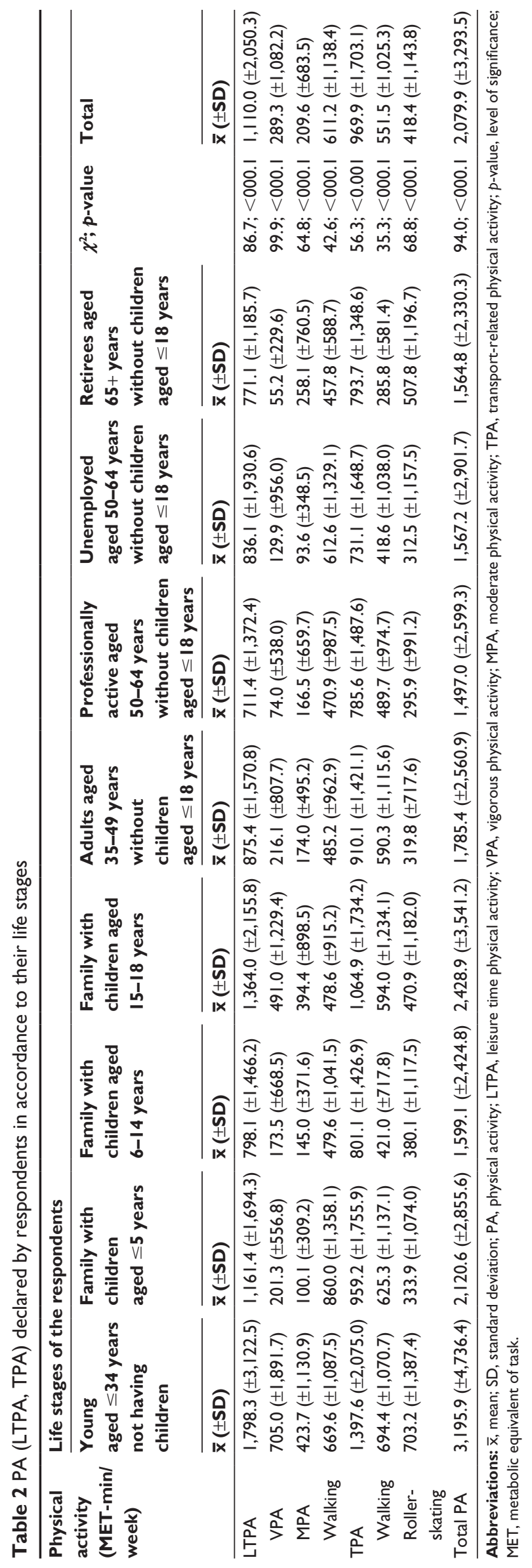


young people aged $\leq 34$ years not having children [423.7 $( \pm 1,130.9) \mathrm{MET}-\mathrm{min} / \mathrm{week}]$ and from families with children aged 15-18 years [394.4 ( \pm 898.5$)$ MET-min/week]. Unemployed aged 50-64 years without children aged $\leq 18$ years undertook PA least often [93.6 $( \pm 348.5)$ MET-min/week]. Retirees aged $65+$ years without children aged $\leq 18$ years [457.8 ( \pm 588.7$)$ MET-min/week] and people from families with small children aged $\leq 5$ years $[860.0( \pm 1,358.1)$ MET$\mathrm{min} /$ week] walked most often.

Similar differences were noted in the case of TPA $(p<0.001)$. Walking was most often associated with young people aged $\leq 34$ years not having children $[694.4( \pm 1,070.7)$ MET-min/week] and least often with the unemployed aged 50-64 years without children aged $\leq 18$ years [418.6 $( \pm 1,038.0)$ MET-min/week] and retirees aged $65+$ years without children aged $\leq 18$ years $[285.8( \pm 581.4)$ MET$\mathrm{min} / \mathrm{week}$ ]. Young people aged $\leq 34$ years not having children were also those who most often cycled or roller-bladed [703.2 ( $\pm 1,387.4)$ MET-min/week]. On the other hand, professionally active and unemployed aged 50-64 years without children aged $\leq 18$ years $[295.9( \pm 991.2)$ and 312.5 $( \pm 1,157.5) \mathrm{MET}-\mathrm{min} /$ week, respectively] and adults aged $35-49$ years without children aged $\leq 18$ years $[319.8( \pm 717.6)$ MET-min/week] chose cycling or roller-skating least often among all groups.

On the basis of time, frequency, and type of PA (LTPA and TPA), the total value of PA was calculated (expressed in MET-min/week), and next, respondents were divided into those meeting and those not meeting the WHO recommendation (specifying pro-health dose of PA). These norms were not met by $37.9 \%$ of respondents (Table 3 ).

In comparison to the most active group, that is, young people aged $\leq 34$ years not having children $(23.6 \%$ not meeting recommendations), the worst results $(p<0.001)$ were revealed by unemployed aged 50-64 years without children aged $\leq 18$ years $(50.4 \%)$, who have more than a three-fold lower chance to achieve WHO norms (OR $=3.28$ [2.15-4.99]). A similar risk is attributed to retirees aged $65+$ years without children aged $\leq 18$ years $(47.6 \%$; $\mathrm{OR}=2.94$ [1.19-7.19]) and professionally active persons aged 50-64 years without children aged $\leq 18$ years $(45.3 \%$; $\mathrm{OR}=2.67$ [1.85-3.85]).

The CHAID decision tree model has indicated multilevel interaction (four levels) among factors through stepwise pathways to meet WHO recommendations (Figure 1). Among all analyzed variables, the strongest relation was observed between meeting WHO criteria and declared current and future sport behavior (nodes 1-4). The first level of the tree was split into four initial branches according to 1) I do not want or cannot practice sport and I do not assume that my situation will change soon; 2) currently, I am not physically active, but if I had such a possibility, I would start practicing sport; 3) sometimes, I practice sport but I need a special incentive (eg, invitation by friends, nationwide actions); 4) I think that sport is health and I try to practice it as often as possible; and 5) sport is my way of life, thus I train everyday. Of course, active persons, grouped in nodes 4 and 5, did not meet these recommendations least often (7.1\%). An analysis acknowledged that life stages were the most prominent variable at the second level of the tree. In case of persons who declared that they are currently not physically active but if they have such possibilities, they would start practicing sport $-56.6 \%$ did not meet WHO norms. They significantly more often included unemployed persons aged 50-64 years without children aged $\leq 18$ years, professionally active persons aged 50-64 years without children aged $\leq 18$ years, and persons

Table 3 OR of meeting WHO recommendations (with $95 \% \mathrm{Cl}$ ) by respondents in accordance to their life stages

\begin{tabular}{|c|c|c|c|c|c|c|}
\hline \multirow[t]{3}{*}{ Life stages of the respondents } & \multicolumn{4}{|c|}{$\begin{array}{l}\text { Recommendations of PA } \\
\text { according to WHO }\end{array}$} & \multirow[t]{3}{*}{ OR $(95 \% \mathrm{Cl})$} & \multirow[t]{3}{*}{$p$-value } \\
\hline & \multicolumn{2}{|c|}{ Meeting } & \multicolumn{2}{|c|}{$\begin{array}{l}\text { Not } \\
\text { meeting }\end{array}$} & & \\
\hline & $\mathbf{n}$ & $\%$ & $\mathbf{n}$ & $\%$ & & \\
\hline Young aged $\leq 34$ years not having children & 239 & 76.4 & 74 & 23.6 & - & - \\
\hline Family with children aged $\leq 5$ years & 243 & 66.9 & 120 & 33.1 & $1.60(1.13-2.24)$ & 0.007 \\
\hline Family with children aged 6-14 years & 182 & 56.2 & 142 & 43.8 & $2.52(1.79-3.54)$ & 0.0001 \\
\hline Family with children aged $15-18$ years & 73 & 58.9 & 51 & 41.1 & $2.26(I .45-3.5 I)$ & 0.0003 \\
\hline Adults aged $35-49$ years without children aged $\leq 18$ years & 64 & 59.8 & 43 & 40.2 & $2.17(1.36-3.46)$ & 0.001 \\
\hline Professionally active aged $50-64$ years without children aged $\leq 18$ years & 127 & 54.7 & 105 & 45.3 & $2.67(1.85-3.85)$ & 0.0001 \\
\hline Unemployed aged $50-64$ years without children aged $\leq 18$ years & 69 & 49.6 & 70 & 50.4 & $3.28(2.15-4.99)$ & 0.0001 \\
\hline Retirees aged $65+$ years without children aged $\leq 18$ years & 11 & 52.4 & 10 & 47.6 & $2.94(1.19-7.19)$ & 0.018 \\
\hline Total & 1,008 & 62.1 & 615 & 37.9 & & \\
\hline
\end{tabular}

Abbreviations: PA, physical activity; WHO, World Health Organization; OR, odds ratio; $p$-value, level of significance. 


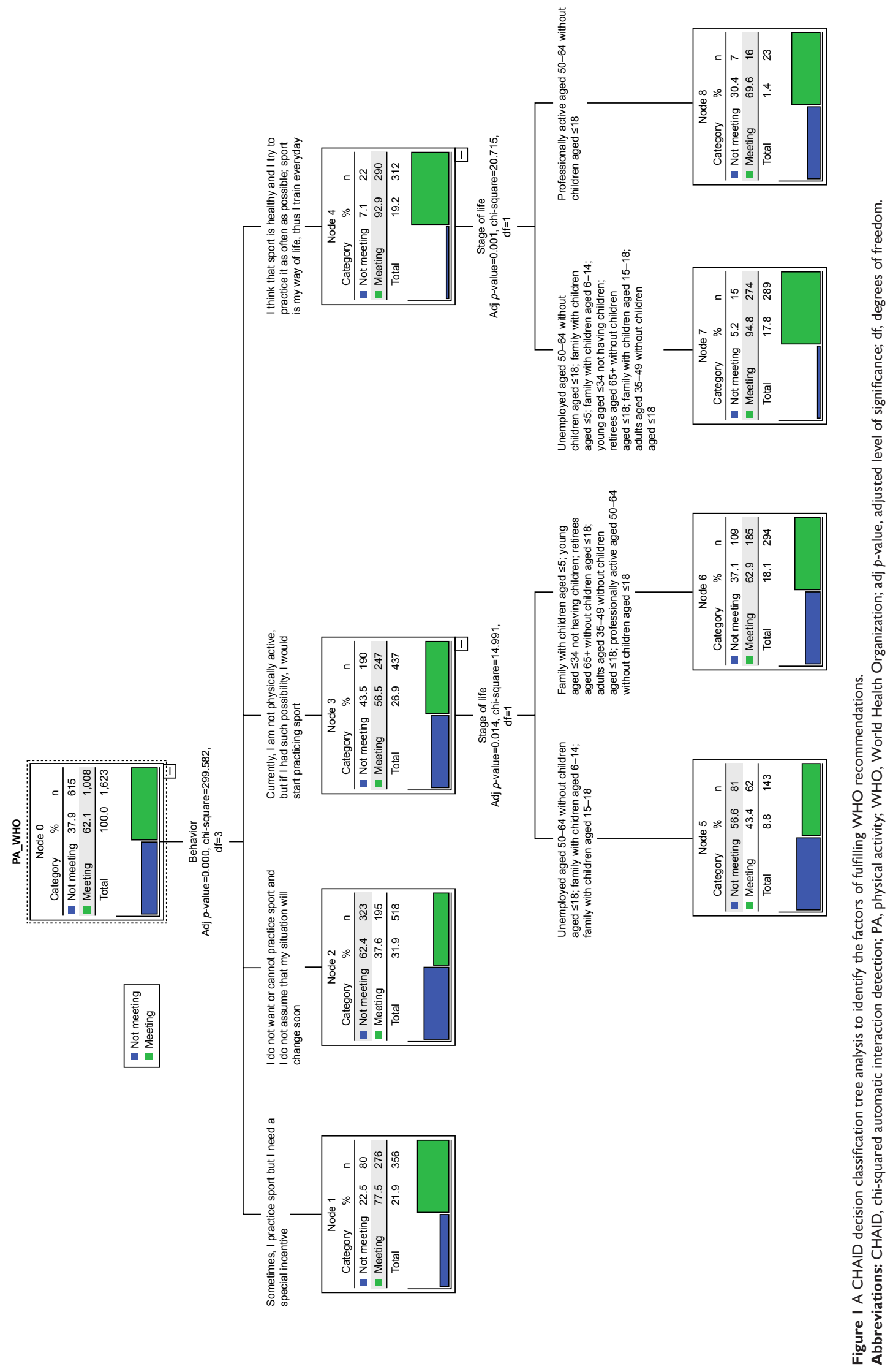


from families with children aged 15-18 and 6-14 years. Other variables (practiced disciplines of sport, using and satisfaction with sport infrastructure in the place of living) did not reach significance for inclusion in the model.

As current and future sport behavior of respondents turned out to be the best predictor variable for meeting WHO recommendations in the first level of CHAID, a detailed analysis was conducted. Significant differences $\left(\chi^{2}=269.2\right.$; $p<0.0001)$ in their declarations were stated, depending on life stages. So, the oldest respondents (from the last two stages) more often stated that they do not want or cannot practice sport and do not think that their situation will change soon. In case of retirees aged $65+$ years without children aged $\leq 18$ years, the fraction of such respondents amounted to $65.0 \%$, and in case of unemployed people aged 50-64 years without children aged $\leq 18$ years $-61.5 \%$.

Currently not active but if given the possibility, would start practicing sport - this was most often declared by persons from families with small children aged $\leq 5$ years (35.4\%) and unemployed people aged 50-64 years without children aged $\leq 18$ years $(35.0 \%)$.

I sometimes practice sport but I need a special incentive (eg, invitation by friends, a nationwide action) - this statement was declared by as much as $36.9 \%$ of young people (aged $\leq 34$ not having children).

On the other hand, only $1.8 \%$ respondents stated that sport is their way of life and they practice it everyday. Most often, these were young people aged $\leq 34$ years not having children $(3.8 \%)$ or adults aged $35-49$ years without children aged $\leq 18$ years $(3.6 \%)$. Young people aged $\leq 34$ years not having children $(29.7 \%)$ and persons classified in the group of family with children aged 15-18 years (25.0\%) more often regarded that sport is health and tried to practice it as often as possible (however, it must be noted that the size was small: $\mathrm{n}=30$ ).

The popularity of particular disciplines of sport and the availability of sport and recreation infrastructure were analyzed only on the basis of answers of active persons $(n=310)-$ that is, stating that 1$)$ sport is health and will try to practice it as often as possible and, that 2) sport is their way of life and they practice it every day. The most popular activities turned out to be (regardless of life stage): cycling (37.4\%), working out in a gym $(23.6 \%)$, swimming $(21.6 \%)$, running/jogging (21.3\%), and playing football (15.2\%).

According to declarations of persons who 1) acknowledged presence of sport and recreation facilities in the neighborhood ( $\leq 30$ minutes of walking distance) and people who 2 ) often or very often used them, the most often attended facilities included a gym (indoor $-12.1 \%$; outdoor $-8.8 \%$ ), a roofed and an open swimming pool (10.7\% and $7.9 \%$, respectively), a sport hall (6.1\%), and an ice rink (6.1\%).

Indoor gyms (at sport and recreation facilities) were used mainly by young people: aged $\leq 34$ years not having children $(21.1 \%)$ and from families with small children aged $\leq 5$ years $(14.0 \%)$, while outdoor gyms were used by retirees aged $65+$ years without children aged $\leq 18$ years $(33.3 \%)$ and adults aged $35-49$ years without children aged $\leq 18$ years (13.6\%). Using a 5-grade scale, for satisfaction in using these two facilities, the aforementioned groups evaluated them at, respectively, 4.2 and 4.5 (in case of indoor gyms) and 4.0 and 3.1 (in case of outdoor gyms).

Indoor swimming pools were visited especially by families with children aged $6-14$ and $\leq 5$ years $(19.0 \%$ and $12.5 \%$, respectively) and young people aged $\leq 34$ years not having children (16.5\%). The level of satisfaction in using a local swimming pool was 4.1, 4.0, and 3.7.

\section{Discussion}

This work acknowledges that it is necessary to consider people's life stages in Polish promotional activities. Results show that in the whole group of studied Poles, WHO recommendations are not met by nearly $40 \%$ respondents; most often, these are people from the last three stages - professionally active people aged 50-64 years without children ( $p<0.0001 ; 46.1 \%)$, unemployed people aged 50-64 years without children $(p<0.0001 ; 50.3 \%)$, and retirees aged $65+$ years without children $(p<0.05 ; 47.6 \%)$. Eurobarometer estimates the share of European Union citizens who either do not exercise, or do it sparsely, at 59\%. ${ }^{40}$ According to WHO, still nearly one-quarter of the people in the world (23.3\%) do not realize the level of activity necessary to maintain health. ${ }^{37}$ Current interventions aimed at increasing PA seem to be insufficient. ${ }^{4,41}$ They are often targeted at motivated groups as they tend to recruit participants who are already active and some have noted difficulty in recruiting participants who were sufficiently inactive. ${ }^{42,43}$ It appears that people who are already active are open to becoming more active. Researchers state that recovery programs should consider life stages and related life events, as they can significantly influence behavior of people. At the same time, they emphasize that this field is poorly analyzed. ${ }^{1}$ The fact of a relationship between realization of pro-health norms of $\mathrm{PA}$ and a life stage is acknowledged by CHAID tree (Figure 1).

Our study shows that the problem of inactivity of Poles starts at the age of 50 years and concerns mainly those who have no parental responsibilities. A special group among 
them is of unemployed people. The percentage of inactive persons is the highest among this group (50.4\%). They undertake MPA in leisure time least often [93.6 $( \pm 348.5)$ MET-min/week]. Their locomotive activity is also the lowest [731.1 $( \pm 1,648.7)$ MET-min/week]. They relatively more often $(p<0.0001)$ declare that they do not want or cannot practice sport and do not intend that this will change soon. Is unemployment demobilizing? There are numerous negative consequences of unemployment among people of working age. One of them is social isolation; those who experience long-term unemployment are more vulnerable than people who are professionally active. ${ }^{44}$ Another reason is the loss of an everyday contact with acquaintances. ${ }^{45}$ Withdrawal of friends and family (due to embarrassment and/or necessity of limiting expenditures related with socialization $)^{45}$ makes the effects of social isolation and unemployment enforce themselves. Everyday frustration and problems disturb adherence of PA, joy of exercises, and efficiency in their systematical undertaking. ${ }^{46}$ Is increase of PA in this group possible? A total of $18.2 \%$ of analyzed unemployed persons declare that currently they are not physically active but when a possibility arises, they would start practicing sport; thus, there is a chance. The lack of identifying with sports does not mean that this will never happen. ${ }^{47}$ It is necessary to facilitate taking up PA to the unemployed Poles. They should have access to sport and recreation facilities (often too expensive for them) for free. It is essential to develop proper programs or activation and make these people aware of the necessity and advantages of undertaking PA. Perhaps, programs of this type should be offered by job centers with which the unemployed are in contact (similar to computer skills courses, for example). Maybe they should organize group classes that would mobilize participants to regular training, which would activate them.

It is known that retiring leads to a drop of PA related with professional work. ${ }^{8}$ However, researchers present evidence that regression is not compensated by a growth of LTPA. ${ }^{48}$ Although some data point to a possible increase of declared PA of people aged $\geq 65$ years, ${ }^{49}$ objective data (supervised) indicate tendencies of its drop. ${ }^{50,51}$ According to studies, over a half of elderly people (52\%) are not engaged in LTPA ${ }^{52}$ despite the fact that, objectively perceiving, the possibilities of being more physically active after retirement are higher. This is also observed in Poland. As many as $47.6 \%$ of retirees do not realize the proper dose of PA necessary to maintain health. In this group, VPA during leisure time [55.2 ( \pm 229.6$)$ MET-min/week] is significantly lower $(p<000.1)$ than in other groups. A similar case is observed with recreational walking $[p<000.1 ; 457.8( \pm 588.7)$ MET-min/week $]$ and transportation walking $[p<000.1 ; 285.8$ ( \pm 581.4$)$ MET$\mathrm{min} /$ week]. Why does this happen? Unsurprisingly, VPA is replaced by other types of effort. ${ }^{8}$ What proves that PA generally drops? Time of retirement is accompanied by events that can have a negative influence. Disability, death of a spouse, and age - these can be crucial factors making exercise impossible. According to the Polish Central Statistical Office, ${ }^{53}$ age does not exclude from practicing sport as many as $36.4 \%$ of people aged $\geq 60$ years. Aging and related health problems and functional limitations (being a barrier ${ }^{54}$ not observed at younger age ${ }^{55-57}$ ) can have a relationship with the physiological inability to undertake some forms of activity. ${ }^{8}$ It is acknowledged by declarations of Polish retirees who relatively more often $(p<0.0001)$ declare that they do not want or cannot practice sport and do not intend that this will change soon. Studies by Biernat and Buchholtz ${ }^{54}$ point to the fact that an illness/doctor's contraindications are a frequent excuse for elder people. However, there is no evidence that PA is harmful (apart from a few contraindications). ${ }^{58,59}$ Of course, education plays an important role (eg, in understanding illnesses or a reliable self-evaluation of health) ${ }^{60}$ and is the responsibility of health service employees. Lack of advice and recommendations concerning PA during medical visits is a lost chance to overcome an aversion to exercising and explaining inactivity by a poor health status. ${ }^{61}$ Health service needs to be included in promotional activities. Lets start with that on every prescription, which would include the note "Physical activity in every prescription." ${ }^{54}$ It can draw attention to the necessity for prescribing it, at the same time having an influence on recipients. It has been proven that employees of health service who engage in developing exercise programs maintain a high level of PA. ${ }^{62}$ This will be helpful, as Polish doctors do not generally serve as a good role model. ${ }^{63}$

Retirees aged $\geq 60$ years like to cycle. Their daily cycling time (recreational or for transport) is about 60.3 minutes. They use a bike as a means of transport more often $(p<000.1)$ than other analyzed groups $[507.8( \pm 1,196.7)$ MET-min/week]. They like to train at outdoor gyms (33.3\%). They evaluate satisfaction with using them at 4.0 (in 5-grade scale). This should be utilized. Less popular indoor gyms (opened regardless of the weather) should be popularized. Adult persons do not regard themselves as addressees of this offer. They regard them as natural forms of organization but mainly for young people. ${ }^{64}$ It is necessary to make these facilities more accessible. It is important to facilitate a contact, maybe through platforms of cooperation with clubs and promoting 
each form of LTPA as forms of compensating a drop of PA after retiring. ${ }^{8}$

Polish high-risk groups include also persons who are professionally active and aged 50-64 years not having children. This group included as much as $46.1 \%$ of physically inactive persons. They are characterized by the lowest LTPA $(p<0.001)$ of all analyzed respondents [711.4 $( \pm 1,372.4)$ MET-min/week], including the lowest VPA $[74.0( \pm 538.0)$ MET-min/week]. TPA is one of the lowest $[785.6( \pm 1,487.6)$ MET-min/week]. This is not an isolated phenomenon. American media show that $<5 \%$ of adults exercise for about 30 minutes a day. ${ }^{51}$ The percentage for Europe is $9 \% .{ }^{40} \mathrm{~A}$ basic barrier for participating in PA of people at this stage of life is lack of time and energy. ${ }^{65}$ They focus on work and career. Shopping, preparing dinner, homework are regarded as priorities, more important than PA. Thus, exercise is not often included in their daily plans (or even at all). The problem is that lives of adults tend to have a regular structure (to a greater extent than during other stages of life). Routine, habitual behavior (including the priority of inactivity) can be moved to other stages of life. ${ }^{66,67}$ It is comforting that in the Polish group of people who are professionally active and aged 50-64 years and not having children $35.0 \%$ admit that they are not physically active but would start practicing sport if they had a chance. This indicates the necessity to provide help and support in this activity. Americans who are physically active state that in order to believe in and be convinced in regular PA and to program it in everyday schedule, it is essential to experience benefits of it. ${ }^{68}$ This suggests that it is necessary to promote such forms that can meet the needs of adults (for example, related with health or emotions). A conviction that they are "obligatory" or "pleasant" can result in a greater probability of their priority treating. Sole knowledge about pro-health advantages is not sufficient in convincing people to participate in PA (especially those inactive ones). Such forms can include cycling that is preferred by professionally active persons aged 50-64 years. As observed in our studies, active representatives of this group cycle for 45.2 minutes a day on average (often to and from work). It is crucial to support employees in this field. This may create unique chances of undertaking PA (through encouraging, providing amenities, donations, motivation, time, and possibility to be active before and after work, or during a lunch break). As routine has a key importance in the life of adults, it is necessary to include PA in everyday schedules. It is important to accent the known advantages of being active (social aspects, wellbeing, and weight control).

\section{Strengths and limitations}

The study provides strong evidence on who are and how to reach groups of particular risk threatened by physical inactivity. It is based on the representative sample of the Polish society and thus enables generalization of results. Most of the studies refer to the contribution of sociodemographic variables to PA while there is a deficit of papers dealing with the prevalence of PA at different life stages.

Limitations of the study should, however, be acknowledged. It relates to cross-sectional data, and thus, long-term changes regarding the level of PA cannot be further analyzed. Thus, it is crucial to conduct further studies that consider a longer period of observations (before and after a life event) and factors that can influence the behavior of respondents. Another limitation is the nature of the questionnaire, and thus the possibility to overestimate or underestimate PA.

\section{Conclusion}

This work shows that life stages and various related events have a significant relation to a drop in the level of PA. Groups having particular risk include adult persons (not having children): professionally active and unemployed aged $50-64$ years and retirees aged $\geq 65$ years. Any attempts of increasing PA or changing tendencies of its decrease should consider quality of life of these persons, as well as their needs, motivations, and barriers. There is a necessity of social support, which means that persons in these stages of life should be target groups of campaigns promoting PA.

\section{Acknowledgments}

This study was administered and funded by the Ministry of Sport and Tourism of the Republic of Poland. This publication was supported by the Warsaw School of Economics and Józef Pilsudski University of Physical Education in Warsaw.

\section{Disclosure}

The authors report no conflicts of interest in this work.

\section{References}

1. Allender S, Hutchinson L, Foster C. Life-change events and participation in physical activity: a systematic review. Health Promot Int. 2008; 23(2):160-172.

2. Bell S, Lee C. Emerging adulthood and patterns of physical activity among young Australian women. Int J Behav Med. 2005;12(4):227-235.

3. Hirvensalo M, Lintunen T. Life-course perspective for physical activity and sports participation. Eur Rev Aging Phys Act. 2011;8(1):13-22.

4. Allender S, Cowburn G, Foster C. Understanding participation in sport and physical activity among children and adults: a review of qualitative studies. Health Educ Res. 2006;21(6):826-835. 
5. Corder K, Ogilvie D, van Sluijs EMF. Invited commentary: physical activity over the life course - whose behavior changes, when, and why? Am J Epidemiol. 2009;170(9):1078-1081.

6. Devine CM, Bove CF, Olson CM. Continuity and change in women's weight orientations and lifestyle practices through pregnancy and the postpartum period: the influence of life course trajectories and transitional events. Soc Sci Med. 2000;50(4):567-582.

7. Raymore LA, Barber BL, Eccles JS. Leaving home, attending college, partnership and parenthood: the role of life transition events in leisure pattern stability from adolescence to young adulthood. $J$ Youth Adolesc. 2001;30(2):197-223

8. Slingerland AS, van Lenthe FJ, Jukema JW, et al. Aging, retirement, and changes in physical activity: prospective cohort findings from the GLOBE study. Am J Epidemiol. 2007;165(12):1356-1363.

9. Chung S, Domino ME, Stearns SC, Popkin BM. Retirement and physical activity: analyses by occupation and wealth. Am J Prev Med. 2009; 36(5):422-428.

10. Allender S, Foster C, Boxer A. Occupational and nonoccupational physical activity and the social determinants of physical activity: results from the Health Survey for England. J Phys Act Health. 2008; 5(1):104-116.

11. Touvier M, Bertrais S, Charreire H, Vergnaud A-C, Hercberg S, Oppert J-M. Changes in leisure-time physical activity and sedentary behaviour at retirement: a prospective study in middle-aged French subjects. Int J Behav Nutr Phys Act. 2010;7:14.

12. Sternfeld B, Ainsworth BE, Quesenberry CP. Physical activity patterns in a diverse population of women. Prev Med. 1999;28(3):313-323.

13. Bell S, Lee C. Does timing and sequencing of transitions to adulthood make a difference? Stress, smoking, and physical activity among young Australian women. Int J Behav Med. 2006;13(3):265-274.

14. Brown WJ, Trost SG. Life transitions and changing physical activity patterns in young women. Am J Prev Med. 2003;25(2):140-143.

15. Leslie E, Owen N, Salmon J, Bauman A, Sallis JF, Lo SK. Insufficiently active Australian college students: perceived personal, social, and environmental influences. Prev Med. 1999;28(1):20-27.

16. Butler SM, Black DR, Blue CL, Gretebeck RJ. Change in diet, physical activity, and body weight in female college freshman. Am J Health Behav. 2004;28(1):24-32.

17. Grace SL, Williams A, Stewart DE, Franche R-L. Health-promoting behaviors through pregnancy, maternity leave, and return to work: effects of role spillover and other correlates. Women Health. 2006;43(2):51-72.

18. Pinto BM, Trunzo JJ, Reiss P, Shiu S-Y. Exercise participation after diagnosis of breast cancer: trends and effects on mood and quality of life. Psychooncology. 2002;11(5):389-400.

19. Mayer DK, Terrin NC, Menon U, et al. Health behaviors in cancer survivors. Oncol Nurs Forum. 2007;34(3):643-651.

20. Eakin EG, Youlden DR, Baade PD, et al. Health behaviors of cancer survivors: data from an Australian population-based survey. Cancer Causes Control. 2007;18(8):881-894.

21. Poudevigne MS, O'Connor PJ. A review of physical activity patterns in pregnant women and their relationship to psychological health. Sports Med. 2006;36(1):19-38.

22. Dahele M, Skipworth RJE, Wall L, Voss A, Preston T, Fearon KCH Objective physical activity and self-reported quality of life in patients receiving palliative chemotherapy. J Pain Symptom Manage. 2007;33(6): 676-685.

23. Satia JA, Campbell MK, Galanko JA, James A, Carr C, Sandler RS. Longitudinal changes in lifestyle behaviors and health status in colon cancer survivors. Cancer Epidemiol Biomarkers Prev. 2004;13(6):1022-1031.

24. Courneya KS, Friedenreich CM. Physical activity and cancer control Semin Oncol Nurs. 2007;23(4):242-252.

25. Kaplan MS, Newsom JT, McFarland BH, Lu L. Demographic and psychosocial correlates of physical activity in late life. Am J Prev Med. 2001;21(4):306-312.

26. Schmitz K, French SA, Jeffery RW. Correlates of changes in leisure time physical activity over 2 years: the Healthy Worker Project. Prev Med. 1997;26(4):570-579.
27. Brown WJ, Heesch KC, Miller YD. Life events and changing physical activity patterns in women at different life stages. Ann Behav Med. 2009; 37(3):294-305.

28. Walsh JME, Pressman AR, Cauley JA, Browner WS. Predictors of physical activity in community-dwelling elderly white women. J Gen Intern Med. 2001;16(11):721-727.

29. Grimby A, Johansson AK, Sundh V, Grimby G. Walking habits in elderly widows. Am J Hosp Palliat Care. 2008;25(2):81-87.

30. Umberson D. Gender, marital status and the social control of health behavior. Soc Sci Med. 1992;34(8):907-917.

31. Gershgoren L, Tenenbaum G, Gershgoren A, Eklund RC. The effect of parental feedback on young athletes' perceived motivational climate, goal involvement, goal orientation, and performance. Psychol Sport Exerc. 2011;12(5):481-489.

32. Fuemmeler BF, Anderson CB, Mâsse LC. Parent-child relationship of directly measured physical activity. Int J Behav Nutr Phys Act. 2011;8:17.

33. Willming C, Gibson H. A view of leisure and patterns of family life in the late 1990s. Soc Leisure. 2000;23(1):121-144.

34. Biernat E. International Physical Activity Questionnaire - Polish long version. Polish J Sports Med. 2013;29(1):1-15.

35. IPAQ [homepage on the Internet]. Guidelines for the data processing and analysis of the International Physical Activity Questionnaire - short and long forms. 2005. Available from: https://sites.google.com/site/theipaq/ scoring-protocol. Accessed February 7, 2018.

36. Pollock ML, Wilmore JH. Exercise in Health and Disease: Evaluation and Prescription for Prevention and Rehabilitation. 2nd ed. Philadelphia: WB Saunders; 1990.

37. WHO. Global Recommendations on Physical Activity for Health. Geneva: WHO; 2010.

38. Kaufman L, Rousseeuw PJ. Finding Groups in Data: An Introduction to Cluster Analysis. Wiley series in probability and mathematical statistics. Hoboken, NJ: Wiley; 2005.

39. Kass GV. An exploratory technique for investigating large quantities of categorical data. Appl Stat. 1980;29(2):119.

40. European Commission. Special Eurobarometer 412. Sport and Physical Activity. Brussels; 2014. Available from: http://ec.europa. eu/health/nutrition_physical_activity/docs/ebs_412_en.pdf. Accessed February 13, 2018.

41. Allender S, Peto V, Scarborough P, Boxer A, Rayner M. Diet, Physical Activity and Obesity Statistics. London: British Heart Foundation; 2006.

42. Browning C, Thomas SA, editors. Behavioural Change: An EvidenceBased Handbook for Social and Public Health. Edinburgh: Elsevier Churchill Livingstone; 2005.

43. Dixon A. Motivation and Confidence: What Does it Take to Change Behaviour? London: King's Fund; 2008.

44. Marcus G, Neumark T, Broome S. RSA projects. Available from: https://www.thersa.org/globalassets/pdfs/blogs/rsa_power_lines_final110511.pdf. Accessed June 25, 2018.

45. Manni JL [homepage on the Internet]. Some thoughts for the unemployed on avoiding the trap of social isolation. 2012. Available from: https://www.psychologytoday.com/us/blog/jobless-not-joyless/201208/ some-thoughts-the-unemployed-avoiding-the-trap-social-isolation. Accessed June 25, 2018

46. Stetson BA, Rahn JM, Dubbert PM, Wilner BI, Mercury M. Prospective evaluation of the effects of stress on exercise adherence in communityresiding women. Health Psychol. 1997;16(6):515-520.

47. Lake J. Young people's conceptions of sport, physical education and exercise: implications for physical education and the promotion of health-related exercise. Eur Phys Educ Rev. 2016;7(1):80-91.

48. Henkens K, van Solinge H, Gallo WT. Effects of retirement voluntariness on changes in smoking, drinking and physical activity among Dutch older workers. Eur J Public Health. 2008;18(6):644-649.

49. Caspersen CJ, Pereira MA, Curran KM. Changes in physical activity patterns in the United States, by sex and cross-sectional age. Med Sci Sports Exerc. 2000;32(9):1601-1609.

50. Davis MG, Fox KR. Physical activity patterns assessed by accelerometry in older people. Eur J Appl Physiol. 2007;100(5):581-589. 
51. Troiano RP, Berrigan D, Dodd KW, Mâsse LC, Tilert T, McDowell M. Physical activity in the United States measured by accelerometer. Med Sci Sports Exerc. 2008;40(1):181-188.

52. Barnes P. Physical activity among adults: United States, 2000 and 2005. Department of Health and Human Services, CDC. MMWR. 2007; 56(46):1209-1212.

53. CSO [homepage on the Internet]. Participation in sports and physical recreation in 2016: statistical information and elaborations. Warsaw; 2017. Available from: http://stat.gov.pl. Accessed February 13, 2018.

54. Biernat E, Buchholtz S. Poor health and contraindications - the most common barriers to poor health and contradictions - the most common barriers to physical activity in Poles aged 50+. Health Problems of Civilization (HPC). 2017;3:135-141.

55. Belza B, Walwick J, Shiu-Thornton S, Schwartz S, Taylor M, LoGerfo J. Older adult perspectives on physical activity and exercise: voices from multiple cultures. Prev Chronic Dis. 2004;1(4):A09.

56. Brawley LR, Rejeski WJ, King AC. Promoting physical activity for older adults: the challenges for changing behavior. Am J Prev Med. 2003; 25(3 Suppl 2):172-183.

57. Cohen-Mansfield J, Marx MS, Biddison JR, Guralnik JM. Socioenvironmental exercise preferences among older adults. Prev Med. 2004;38(6):804-811.

58. Nied RJ, Franklin B. Promoting and prescribing exercise for the elderly. Am Fam Physician. 2002;65(3):419-427.

59. Kostka T. Aktywnośc ruchowa a starzenie się organizmu. In: Jegier A, Nazar K, Dziak A, editors. Medycyna sportowa. Warszawa: Polskie Towarzystwo Medycyny Sportowej; 2013.

60. Ismail H, Wright J, Rhodes P, Small N. Religious beliefs about causes and treatment of epilepsy. Br J Gen Pract. 2005;55(510):26-31.
61. Zimmerman R. Doctor's orders: prescribe exercise to patients, make physical activity a vital sign. 2015. Available from: http:/www.wbur. org/commonhealth/2015/12/10/doctors-prescribe-exercise-to-allpatients. Accessed February 13, 2018.

62. McPhail SM, Schippers M, Marshall AL, Waite M, Kuipers P. Perceived barriers and facilitators to increasing physical activity among people with musculoskeletal disorders: a qualitative investigation to inform intervention development. Clin Interv Aging. 2014;9:2113-2122.

63. Biernat E, Poznańska A, Gajewski AK. Is physical activity of medical personnel a role model for their patients. Ann Agric Environ Med. 2012;19(4):707-710.

64. Nowak S, Wierzbicki R. Diagnoza społeczna zapotrzebowania na infrastrukturę sportowo-rekreacyjna. Raport z badania jakościowego $i$ omnibusowego. Warszawa; 2016. Available from: https://www.gov.pl/ sport-turystyka/diagnoza-spoleczna-zapotrzebowania-na-infrastrukturesportowo-rekreacyjna. Accessed June 25, 2018.

65. Hyde AL, Maher JP, Elavsky S. Enhancing our understanding of physical activity and wellbeing with a lifespan perspective. Int $J$ Wellbeing. 2013;3(1):98-115.

66. Verplanken B, Wood W. Interventions to break and create consumer habits. J Public Pol Marketing. 2006;25(1):90-103.

67. Wood W, Neal DT. A new look at habits and the habit-goal interface. Psychol Rev. 2007;114(4):843-863.

68. Victorian Health Promotion Foundation [homepage on the Internet]. Victorians' physical activity across life stages: insights to engage Victorians in physical activity at different life stages. Available from: https://www.vichealth.vic.gov.au/-/media/ResourceCentre/PublicationsandResources/Life-Stages/VH_Life-stages_Info-sheet.pd. Accessed June 25, 2018.
Clinical Interventions in Aging

\section{Publish your work in this journal}

Clinical Interventions in Aging is an international, peer-reviewed journal focusing on evidence-based reports on the value or lack thereof of treatments intended to prevent or delay the onset of maladaptive correlates of aging in human beings. This journal is indexed on PubMed Central, MedLine,

\section{Dovepress}

CAS, Scopus and the Elsevier Bibliographic databases. The manuscript management system is completely online and includes a very quick and fair peer-review system, which is all easy to use. Visit http://www.dovepress. com/testimonials.php to read real quotes from published authors. 